\title{
Is Standard Dutch with a regional accent standard or not? Evidence from native speakers' attitudes
}

\author{
Stefan Grondelaers and Roeland van Hout \\ Radboud University of Nijmegen
}

A B S T R AC T

\begin{abstract}
This paper reports a speaker evaluation experiment that investigated the competition between three regional accents of Standard Dutch and references to the speaker's profession as determinants of attitude formation. A stratified sample of listenerjudges rated speech stimuli that were presented in two guises, a neutral guise and a teacher guise (the latter containing multiple references that revealed the speaker to be a high school teacher of Dutch). The experimental findings corroborate our earlier claim that regional flavoring is embedded in lay conceptualizations of Standard Dutch. Although teachers of Dutch may be the last "gatekeepers" of the standard in the Low Countries, they are not automatically downgraded when they have a regional accent: What matters is, clearly, which accent they have. Analysis of the ratings further suggests a hierarchical relation between accent and occupation as perception triggers: Even though regional accent clearly is the stronger attitude determinant, it does not suppress occupational information but interacts with it to generate richer social meaning.
\end{abstract}

It is an uncontroversial fact that Standard Dutch is used as the everyday language in a wide range of usage contexts by all the Dutch (see Smakman, 2006:34, and the references cited there). This spoken standard resembles the formal language register as spoken in the Randstad. ${ }^{1}$ Stroop (2000a) suggested that the acceptance of this norm was successfully promoted by the Dutch authorities before World War II.

Equally uncontroversial is the fact that this robust standard is currently undergoing substandard extensions (as is the case in most European standard languages, see Deumert \& Vandenbussche, 2003). This paper focuses on the question how and to what extent regional accent variation (Adank, Van Hout, \& Van de Velde, 2007) affects standard language and standard language ideology in The Netherlands. In a previous speaker evaluation experiment (Grondelaers, Van Hout, \& Steegs, 2010), we found that regional flavoring is subconsciously acceptable and socially meaningful to naïve listeners, which confirmed the often articulated suspicion that the Dutch are growing increasingly tolerant of some variation in the standard (Smakman, 2006:54). In the cited experiment, however, "neutral" standard speakers were evaluated, of whom nothing was expected in the way of regional neutrality. Is a regional accent also acceptable and meaningful for speakers who are not (or less) supposed to have a regional accent? In order to answer that question we conducted a new experiment in 
which teachers of Dutch from three accent regions were presented in a neutral guise - without references to their profession - and in a teacher guise, in which they repeatedly revealed themselves to be high school teachers of Dutch. This manipulation also enabled us to investigate whether regional accent is still the most potent attitude trigger when competing with explicit social cues. In Grondelaers et al. (2010), we found that regional accent is by far the strongest attitude trigger when competing with other low- and high-level linguistic cues. But what happens when a speech sample contains accent triggers as well as social cues? Is it socially more meaningful to know that a speaker comes from the Limburg province (a rural culture traditionally associated with low prestige stereotypes) than that he is an educated professional?

The text is organized as follows. In the background section, we outline standard language ideologies in The Netherlands and review the available evidence pertaining to the perception of accent variation and the image of secondary school teachers in The Netherlands. The subsequent section reports the design and results of the new investigation into the attitudes the Dutch hold against accented Standard Dutch as spoken by teachers and by professionally neutral speakers. The general discussion reviews the theoretical consequences of the experimental findings.

\section{B A C K G R O U N D}

Although the Dutch that is spoken in The Netherlands meets the standardization criteria outlined in Haugen (1966) (see De Vries, 1987; Smakman, 2006), there is some controversy as to how standard Standard Dutch (still) is. As in other European standard languages (Deumert \& Vandenbussche, 2003), the recent history of Netherlandic Dutch is characterized by substandardization phenomena that give rise to conflicting opinions about the future of Dutch. Three substandardization phenomena have by now been widely recognized (see Grondelaers \& Van Hout, forthcoming). Whereas the lowered pronunciation of some diphthongs in Standard Dutch (Stroop, 1998; Van Bezooijen, 2001; Jacobi, 2008) and the progressing regional accent variation in Standard Dutch (Smakman, 2006; Adank et al., 2007) are phonetic changes that excite little irritation, the rapid dissemination of the subject use of the object pronoun hun (Van Hout, 2003, 2006) is explicitly rejected as nonstandard.

Yet, increasing variability in the production of Standard Dutch is not, in itself, indicative of increasing nonstandardness. Language is in constant flux, and even among prototypical standard speakers of Dutch, there is evidence of variation (Smakman, 2006). The basic question to ask, therefore, is how and to what extent the increasing variability is negotiated or constructed in the communal assessment that ultimately determines what is standard or not. The latter amounts to an investigation of Standard Language Ideology (SLI). SLI designates a normative ideology imposed and sustained by institutions such as (formal) education and the media, but maintained by (silent) agreement between the 
language users. The term standard language ideology was coined in Milroy and Milroy (1985:23) to denote "a set of abstract norms to which actual usage may conform to a greater or lesser extent." On a related note, Silverstein (1979) defined linguistic ideology as a "set of beliefs about language articulated by users as a rationalization or justification of perceived language structure and use" (Silverstein, 1979:193; repeated in Woolard, 1998:4).

If the latter is correct, then how do Dutch SLIs reflect and construct the increasing variability in today's Standard Dutch? Early discourses about Standard Dutch are typically conservative. Building on Jespersen's definition of a standard language, Van Haeringen (1924) postulated that cultured Dutch should not contain any trace of the regional origin of the speaker. Although he agreed to some personal variation in the implementation of this ideal, Van Haeringen strictly rejected systematic variation that was indexical of a speaker's geographic origin. It is unlikely, however, that this "strong" ideology ever reflected actual standard usage. Kloeke (1951:8) rejected the regional neutrality ideal of a uniform standard language as a "myth" and estimated that actual competence in a variation-free variety was limited to no more than $3 \%$ of the Dutch (Willemyns, 2003:110).

In addition to this conservative ideology, a Western ideology must be distinguished (see Willemyns, 2003:110, for a related view). In actual practice, the standard variety that emerged between 1920 and 1940 was modeled on the speech of the (upper) middle class inhabitants of the Western cities of the Randstad (Smakman, 2006). This middle-class Randstad variety was promoted through the educational system and the media (Willemyns, 2003:110), though its gradual acceptance appears to be consensus-based rather than enforced. There has always been national agreement that Randstad Dutch is the best variety of Dutch (De Vries, 1987:127-128; Smakman, 2006:162), and the Western dominance is also rooted in the subconscious conceptualizations of the Dutch, who typically award the highest status ratings to Randstad speech (Grondelaers et al., 2010; Heijmer \& Vonk, 2002). A concrete emanation of the Western ideology is the fact that typically Western pronunciation features, such as the diphthongization of the long vowels /e/ and /o/ and the uvular realization of /g/, were previously labeled as substandard but are now considered standard, even by speakers who do not use these features themselves (Willemyns, 2003:120n17).

Prior to the last decades, all ideologies reflect and construct a relatively uniform usage without systematic variation (except the Western bias). In present-day Standard Dutch, however, there is compelling evidence for widespread social and regional accent variation (cf. supra). This new reality has given rise to a complex cluster of ideologies reflected in strongly conflicting discourses and practices. Nevertheless, there are two indications that SLIs are being "relaxed" somewhat to accommodate variability. The first one (cited in Willemyns, 2003:113) concerns the definitions of Standard Dutch forwarded in the two editions of the Algemene Nederlandse Spraakkunst ("General Grammar of Dutch"). Whereas the first edition (Geerts 1984:10) insists on a variation-free definition of Standard Dutch, the second (Haeseryn 1997:16) defines Standard 
Dutch as a "language variety in which no elements appear which clearly stand out as non-general" (1997:16), a characterization which appears to leave room for some variation.

The actual implementation of the standard norm in the Dutch media is also indicative of increased tolerance toward variation. Van de Velde, Van Hout, and Gerritsen (1997) argue convincingly for a "continual interplay between radio language on the national broadcasting stations and standard language," to the extent that radio language is indicative of prevailing opinions on standardness. In this view, the fact that a regionally neutral pronunciation is no longer a prerequisite for Dutch radio presenters (Smakman, 2006:48; Stroop, 2000a) testifies to a gradual acceptance of accented standard speech.

In line with this anecdotal evidence, there appears to be a decreasing willingness on the part of the linguistic establishment, which used to be the driving force in the standardization of Dutch (Geeraerts, Grondelaers, \& Speelman, 1999; Stroop, 2000a), to uphold one uniform best language. Bennis's (2003) contentions that the Dutch language "is no longer the exclusive property of an elitist upper class of the Dutch population" and that "the norm-imposing establishment is us all" are indicative of a "relocation" of the responsibility for standard language maintenance to the layman.

There are, however, forces that oppose the new developments. The refusal of the Nederlandse Taalunie - the highest linguistic authority in the Dutch-speaking countries since its installation in 1980 - to support regional varieties of Dutch (Van Hout, 2007) embodies the conservative ideology that is hostile to variation. So does Stroop's (1998, 2000a, 2000b) rejection of regional varieties as nonstandard. This normative conservatism is also central to explicit evaluations of the standard: In contrast with the norm-relaxing tendencies just cited, regional neutrality is overwhelmingly confirmed by lay speakers of Dutch as the most important characteristic of Standard Dutch (Smakman \& Van Bezooijen, 1997: Figure 2).

Interestingly, this asymmetry between the conservativeness of overt discourses and the change that is suggested by more spontaneous evolutions, namely the increasing tolerance for variation in the media and in the standard grammar, confirms the "division of labour" Kristiansen (2009) found in his investigation of Danish SLIs. Whereas explicit questionnaires into SLIs typically returned the educationbased point of view, to the extent that the best language in Denmark is the official, conservative standard, experimental investigations into subconscious conceptualizations of the standard language increasingly reveal that young Danes award the highest prestige to modern Copenhagen speech. This leads Kristiansen to propose that it is the subconscious evaluations that are the more dynamic structures that reflect language change. For this reason, it is worthwhile to investigate subconscious native speaker attitudes toward accent variation in Standard Dutch. If language attitudes are "socially derived, intellectualized or behavioral ideology" (Woolard, 1998:16), then an investigation into the lay conceptualization of Standard Dutch as spoken by teachers of Dutch will unveil to what extent regional accent variation is publicly legitimized in Standard Dutch. 
Most experimental research into implicit language attitudes builds on the speaker evaluation paradigm pioneered in Lambert, Hodgson, Gardner, and Fillenbaum (1960). In this technique, listener-judges rate recorded samples of language or accent varieties on a number of evaluative scales. On the resulting corpus of ratings, factor analysis is applied to detect the interhearer consistencies across evaluations that are thought to constitute the basic dimensions of the architecture of language attitudes (see Garrett, 2005; Garrett, Coupland, \& Williams, 2003, for an overview and evaluation). Because the standard practice in the speaker evaluation paradigm is to select one's rating scales from a number of basic studies (see Zahn \& Hopper, 1985, for an overview), many studies have found accordingly that their ratings correlate into two or three basic dimensions, typically status, solidarity (social attractiveness), and sometimes also personal integrity.

In the Dutch language area, Heijmer and Vonk (2002) reported a speaker evaluation experiment in which 60 participants rated one audiotaped sample - a transcript of a job interview - representing one of six accents of Dutch. Heijmer and Vonk (2002) confirmed the status- and solidarity-based architecture of Dutch accent attitudes, but they also found that all regional accents obtained virtually identical low scores on the status-dimension. These data reveal that accented Dutch is unacceptable in a job interview situation. In Grondelaers et al. (2010), we discussed two causes for concern in Heijmer and Vonk's (2002) methodology. To begin with, the noncontrastive stimulus presentation method (only one stimulus per respondent) may underspecify available social meanings that would be activated in a more contrastive frame of reference (Abrams \& Hogg, 1987) featuring different accent varieties. In addition, the small number of attitude determinants (status and solidarity) across which accent perceptions are compared may well equalize attitudes that are quite different in reality. In a related experiment, we addressed these concerns by proposing a richer measurement instrument, which integrated 18 scales adapted from a number of scaled approaches to speech evaluation in the Low Countries; the scale-set was specifically constructed with a view to detecting attitudinal regularity beyond the much-replicated status, solidarity, and integrity dimensions. A sample of listener-judges $(n=133)$ that was stratified with respect to age (young $n=60$; old(er) $n=73$ ), gender (male $n=70$; female $n=63$ ), education (within the older group, secondary schooling $n=43$; more than secondary schooling $n=30$ ), and regional background (Rand $n=32$; North $n=24$; Mid $n=24$; South $n=53$ ) rated a Randstad, a South (Limburg), a North (Groningen), and a Mid (Gelderland) accent, each represented by two speakers.

Speakers were selected from the Teacher Corpus (Van Hout, De Schutter, De Crom, Huinck, Kloots, \& Van de Velde, 1999), a database of 80 (informal) sociolinguistic interviews with secondary school teachers of Dutch, stratified for gender, age, and region; teachers were told in advance that their speech was being recorded for inclusion in a corpus of standard Dutch. Interviews centered on teaching experience and literary taste, but also on nonprofessional topics such as health, household arrangements, or recreation. Per speaker, a 20-second 
fragment of unedited spontaneous speech was selected that did not contain any social perception cues (such as references to the speakers' teaching background or social status). In view of the fact that different speakers were involved in the experiment (whose speech was not controlled in any way), each of the samples contained speaker-dependent variables such as voice quality and speech rate, but also higher-level choices such as specific lexical or syntactic choices. Because all of these variables have been shown to trigger or influence attitude formation, one of the advantages of the "ecological" stimuli we used is that the salience of regional accent vis-à-vis other triggers could be tested in a natural, noncontrived environment. Analysis of the ratings confirmed that regional accent was by far the most important perception trigger in the presented language samples. As predicted, the factor analysis returned a comparatively richer attitude architecture than in most other speaker evaluation work. Whereas the analysis confirmed the basic dimensions speaker status and speaker integrity, it also returned two dimensions pertaining to the accents themselves, namely accent status and accent euphony. Unsurprisingly, Randstad speech was considered the most prestigious variety, maximally appropriate for formal interaction. Non-Western accents, however, were not automatically or systematically rejected but indexed rich social meaning. While Southern-sounding speakers were downgraded in terms of prestige, they were upgraded in terms of personal integrity, their speech was rated as the most "euphonic" of the investigated varieties, and their accent was awarded a higher norm status than any of the other non-Western accents. This positive evaluation, moreover, was not an artifact of in-group favoritism. Respondents did not prefer their own accent in any significant way.

Although these data seem to counter Heijmer and Vonk's (2002) claim that what matters is whether speakers have an accent, not which accent they have, we cannot exclude that the social meanings we found are restricted to a neutral speech context in which a regional accent is not sanctioned in any way (whereas Heijmer \& Vonk's stimuli purported to be fragments from formal job interviews, in which applicants typically make an effort to standardize their speech as much as possible). An evident follow-up question would therefore be whether we can replicate the accent-triggered social meanings when speakers are evaluated whose accent does matter. What happens, more particularly, when our speakers reveal themselves to be teachers of Dutch? Secondary school teachers are the first-line dispensers of standard speech as well as the last gatekeepers of that standard (Van Istendael, 2008:31). Are these acknowledged "guardians of the standard language" (Van de Velde \& Houtermans, 1999) who are supposed to be "loyal to official pronunciation norms" (De Schutter, 1980) downgraded for accented speech, or does regional accent in the speech of teachers of Dutch activate the same range of social meanings as regional accent in socially neutral speech?

Prior experimental work on the connection between diverse perception triggers in impression formation suggests that the impact of regional accent and social cues need not be so extreme that one trigger completely cancels out the other. In a series of investigations into the perceptual connections between two American accents (Southern and gay) and the variable (ING), Campbell-Kibler (2007:33) found 
that (ING) "intensifies and so, in some sense is, part of these two accents." In a follow-up study that focused on (ING)'s central meaning, however, CampbellKibler (2009:142-143) found that the strong links between (ING) and the intelligent/educated percept ("one of the most tempting candidates for a core or central meaning of (ING)" [p. 142]) were qualified in different ways by speaker accent and social class. According to Campbell-Kibler (ibid.), these interactions demonstrate (ING)'s contextual dependence, because "different speakers have different aspects of their identity left open to manipulation by (ING), depending on the other information which is available to the listener."

She then goes on to propose that his sociosemantic flexibility is indicative of an "indexical field" in Eckert's (2008) sense of "a constellation of ideologically related meanings, any one of which can be activated in the situated use of the variable" (rather than of one contextually constant meaning). In much the same way, the teaching profession indexes an array of different social meanings. ${ }^{2}$ Verhoeven, Aelterman, Rots, and Buvens (2006) concluded that Belgian high school teachers enjoy a positive image in spite of "the status inconsistency with which teaching has to contend" (pp. 497-498): whereas teachers were ranked lower in terms of salary than other professions, they were perceived better in terms of social utility. On average, teachers were assessed lower in terms of knowledge and prestige but the differences were minimal. The results with regard to the status dimension were strongly dependent on the occupations to which teaching was compared. Although Verhoeven et al. (2006:482) cited evidence that showed that the teacher trade is generally appreciated in The Netherlands, here too the picture is ambivalent, because there is also evidence that supports a more negative image (see, for example, Oudejans \& Meesters, 1998).

AN EXPERIMENTAL INVESTIGATION INTO ACCENT AND

OCCUPATION AS ATTITUDE DETERMINANTS

\section{Methods}

Speech stimuli. From the Teacher Corpus, two speakers were selected for each of the three accents that were correctly identified in more than $75 \%$ of all cases in Grondelaers et al. (2010), namely the Randstad accent (Rand), the Northern accent (North), and the Southern accent (Limburg). Per speaker, a neutral guise and a teacher guise were subsequently constructed. Although we made a plea in Grondelaers et al. (2010) for the use of spontaneous speech stimuli in speaker evaluation experiments, we were unable to find any 20 -second stretches of running speech in our interviews on the basis of which speakers could univocally be identified as teachers. In order to implement the social variable, we therefore had no choice but to assemble 20-second samples from 3-, 4-, and 5 -second snippets of running discourse. In the + teacher guise, all snippets contained an unmistakable reference to teaching, students, or didactic methodology, whereas the -teacher guise contained no reference whatsoever to 
teaching. All snippets were faded around the edges, and all speech stimuli were digitally smoothed in order to approximate as much as possible the character of fluent speech.

In order to address the possible confounds this guise-construction technique introduces, we piloted the resulting set of stimuli in a preliminary experiment with a group of participants (not included in the main experiment) who rated the samples with respect to the social traits "interesting" and "effeminate" and with respect to speaker occupation and accent identifiability. This preexperiment confirmed that speakers were correctly identified as teachers in the teacher guise but never in the neutral guise, and that neither guise received significantly different scores for the social traits. More importantly, the preliminary data also demonstrated that the regional origin of a speaker was never significantly more or less identifiable in the teacher than in the neutral guise. The latter is a pivotal control because the teacher and neutral guise of the same speaker contain different linguistic materials that need not cue the regional origin of the speaker to the same extent. If, for example, a "soft" nonuvular /g/ betrays the Southern origin of a speaker to a larger extent than other phonemes, a higher frequency of words containing a /g/ in one guise may lead to an easier or faster identification of that speaker as Southern in that guise. The fact that we did not control for such distributions over the guises apparently did not affect perceived accent strength much; the question must therefore be raised whether the perception of a given accent correlates linearly with the number of "cue phonemes" for that accent. Although this correlation is supported by quantitative evidence (Cunningham-Anderson \& Engstrand, 1989), other evidence indicates that the perception of accent strength is not determined in any linear way by the number of intrinsic accent features. Cargile (2002), for instance, selected speakers of African American Vernacular English (AAVE) on the basis of intersubjective consensus of accent strength and quantity of AAVE phonological features. The fact that an African American female, whose speech contained 14 phonological features of AAVE, was correctly identified by $91.8 \%$ of the listener-judges as African American, whereas an African American male with no less than 18 AAVE phonological features in his speech was identified by only $51 \%$ of the respondents, clearly illustrates that there is no linear relation between subjective and objective correlates of accent strength. The inevitable conclusion with respect to accent identifiability in Cargile's and our own data must be that there are other, less quantifiable factors that determine accent perception. It is unlikely that these factors distribute differently over different guises.

Evaluative scales. Scales used in this experiment were based on the scale-set tested and implemented in Grondelaers et al. (2010). An extensive justification can be found there. In total, speech stimuli were evaluated on 20 scales, 13 of which represented bipolar semantic differentials rated on five-point scales. Listenerjudges were asked to evaluate speakers on the scales cozy, social, modest, nice, open, honest, civilized, intelligent, educated, and their speech on the scales soft, fast, melodious. The order of the bipolar antonyms was varied so that scales 
sometimes started with a positive quality (e.g., nice) and sometimes with a negative quality (e.g., monotonous).

In addition, there were six Likert statements (rated on five-point scales) presented in two groups of three statements (According to you, this speaker speaks like a minister, a news anchor, prince Willem Alexander and The way this speaker speaks, you should speak with a news anchor, during a job interview, with the queen). The stimulus speaker's purported regional origin, finally, was elicited on a map of the Low Countries, to which the names of the provinces had been added. Listener-judges were asked to mark the stimulus speaker's assumed regional origin with a circle.

Listener-judges. We interviewed a sample of 240 listener-judges, equally divided over the three accent regions included in the experiment $(n=80$ per region). All listener-judges were students of various backgrounds who did not, however, major in linguistics or social psychology. They were interviewed at the University of Groningen (= North) or university colleges in Heerlen and Sittard (Limburg = South) and Den Haag (Randstad= Rand). On average, listenerjudges were 21.45 years old (ranging between 17 and 28 years); 120 listenerjudges were male, 120 were female.

Procedure. Speech fragments were played from laptops complemented with headphones. Respondents only evaluated 6 of the 12 speech stimuli (two guises for six speakers) included in the design. One-half of the respondents (Condition 1) evaluated the neutral guise for Rand1 (i.e., the first Randstad-speaker), North1, and South1 and the teacher guise for Rand2 (i.e., the second Randstadspeaker), North2, and South2, whereas the other half of the respondents (Condition 2) rated the teacher guise for Rand1, North1, and South1 and the neutral guise for Rand2, North2, and South2. As a result, no listener-judge evaluated the two guises of one speaker. Respondents were given an experimental set of seven response sheets, the first six of which contained the 20 experimental scales for each of the six stimuli, whereas the last contained some demographic variables pertaining to the listener-judge. The general instruction provided for all respondents was that they were participating in an experiment concerned with how people rate personalities on the basis of limited information (Abrams \& Hogg, 1987:205).

\section{Results}

In this section, we report the results of the analysis, which will be fleshed out in the subsequent discussion section. Accent identifiability was computed on the level of accent region (Rand, South, North). Table 1 contains, on the vertical axis, the six stimulus speakers included in the experiment and, on the horizontal axis, the regions to which they were attributed, as well as the relative frequency of actual attributions per speaker. Mid refers to the area corresponding to the Gelderland province, which is geographically speaking the middle area at the country's eastern border. Flanders refers to the Dutch-speaking part of Belgium. 
TABLE 1. Regional identification (6 regions; columns) of tested accents (6 speakers from 3 regions; rows)

\begin{tabular}{lcccrrr}
\hline \hline & Rand & North & South & Mid & Flanders & Missing \\
\hline Rand1 & 64.6 & 9.6 & 7.9 & 14.6 & 0.0 & 3.3 \\
Rand2 & 67.9 & 12.1 & 8.3 & 9.6 & 0.4 & 1.7 \\
North1 & 13.3 & 57.5 & 9.6 & 17.5 & 0.8 & 1.2 \\
North2 & 41.2 & 32.9 & 5.0 & 16.2 & 1.2 & 3.3 \\
South1 & 4.2 & 7.9 & 55.8 & 5.8 & 15.4 & 10.8 \\
South2 & 12.5 & 5.8 & 64.2 & 8.3 & 7.1 & 2.1 \\
\hline \hline
\end{tabular}

On the ratings matrix, a principal component analysis (PCA) was carried out (SPSS, procedure factor analysis). An analysis with factor selection criterion eigenvalue $>1$ and varimax rotation yielded a four-component solution that accounted for $57.9 \%$ of the variance in the data. Table 2 contains the 19 scales and their loadings on the four principal components (for interpretative convenience, boldface shading was added to factor loadings >.5). This PCAsolution yielded three robust components that can be labeled speaker status, speaker integrity, and speaker competence. These components were confirmed in all PCAs on splits of the material according to gender, respondent region, guise (neutral vs. teacher guise), and experimental condition. Although it is tempting to label the fourth component accent euphony-on account of the scales soft and fast that load on it - the fact that melodious does not load on it, as well as the fact that the component does not consistently emerge in PCAs on the splits of the material, raises concern. We will therefore restrict all further analyses to the three first components. A PCA without the scales soft and slow confirms the three-component solution, accounting for $60 \%$ of the variance in the data.

Analyses of variance (ANOVAs) with repeated measures were carried out to test the effects of the manipulated variables accent region and professional occupation (both within-subjects effects) and condition (between-subjects) on the components competence, status, and integrity. The component scores for the ANOVAs were calculated by averaging over the scores on the relevant scales (see the boldfaced scales in Table 2; scales with a negative loading were recoded). In these ANOVAs, data for the two speakers from each of the three regions were pooled because respondents evaluated a speaker in only one of his guises. Condition as a main effect was significant for competence only $(F(1,216)=6.177, p=.014$; status: $F<1$, integrity: $F<1$ ), and in all but one interaction. However, the impact of region and occupation was always larger in terms of explained sum of squares (SS) than the impact of the interactions involving condition (SS of region and occupation vs. all interactions involving condition; on competence: 76.581 vs. 69.528 ; on status: 82.690 vs. 77.273 ; on integrity: 11.635 vs. 6.562 ).

The effects of region and occupation, including their interaction, were all significant with one exception. Two effects were significant for competence 
TABLE 2. Factor loadings for 19 scales on 4 principal components after varimax rotation

\begin{tabular}{lccrr}
\hline \hline & $\begin{array}{c}\text { Speaker } \\
\text { Status }\end{array}$ & $\begin{array}{c}\text { Speaker } \\
\text { Integrity }\end{array}$ & $\begin{array}{c}\text { Speaker } \\
\text { Competence }\end{array}$ & $\begin{array}{r}\text { (Accent } \\
\text { Euphony?) }\end{array}$ \\
\hline Beautiful & 0.304 & -0.373 & 0.484 & 0.020 \\
Cozy & 0.045 & $\mathbf{- 0 . 7 1 7}$ & -0.097 & -0.018 \\
Social & 0.070 & $\mathbf{- 0 . 6 1 4}$ & 0.318 & 0.180 \\
Modest & 0.046 & $\mathbf{- 0 . 5 4 4}$ & 0.077 & 0.380 \\
Not nice & -0.077 & $\mathbf{0 . 7 9 2}$ & -0.102 & -0.173 \\
Closed & -0.071 & $\mathbf{0 . 7 8 8}$ & 0.015 & 0.155 \\
Dishonest & -0.109 & $\mathbf{0 . 7 0 1}$ & 0.001 & 0.136 \\
Civilized & 0.356 & -0.063 & $\mathbf{0 . 7 0 7}$ & -0.068 \\
Smart & 0.253 & -0.123 & $\mathbf{0 . 7 7 8}$ & -0.075 \\
Lowly educated & -0.236 & 0.081 & $-\mathbf{0 . 7 2 0}$ & 0.166 \\
Soft & -0.113 & -0.157 & 0.023 & $\mathbf{0 . 7 8 7}$ \\
Fast & 0.039 & -0.071 & 0.263 & $-\mathbf{0 . 6 7 8}$ \\
Melodious & 0.103 & -0.430 & 0.365 & 0.117 \\
Like a minister & $\mathbf{0 . 7 1 4}$ & 0.038 & 0.313 & -0.110 \\
Like a news anchor & $\mathbf{0 . 7 7 4}$ & -0.033 & 0.210 & -0.134 \\
Like prince Willem- & $\mathbf{0 . 6 9 2}$ & 0.012 & 0.111 & -0.064 \\
$\quad$ Alexander & & & & \\
Norm_news anchor & $\mathbf{0 . 8 0 9}$ & -0.118 & 0.159 & -0.028 \\
Norm_job interview & $\mathbf{0 . 7 3 7}$ & -0.201 & 0.221 & 0.007 \\
Norm_queen & $\mathbf{0 . 7 6 4}$ & -0.098 & 0.129 & 0.092 \\
\hline \hline
\end{tabular}

(region: $F(2,432)=52.930, p=.000 ;$ occupation: $F(1,216)=3.099, p=.08$; occupation by region: $F(2,432)=16.238, p=.000)$. All three effects were significant for status (region: $F(2,432)=64.347, p=.000$; occupation: $F(1,216)$ $=8.855, p=.003$; occupation by region: $F(2,432)=5.889, p=.003)$, and for integrity (region: $F(2,418)=3.449, p=.033$; occupation: $F(1,209)=11.617, p$ $=.001$; occupation by region: $F(2,418)=4.202, p=.016)$. Although both region and occupation significantly influence attitude scores, region is the strongest factor on the competence and status components (SS within subjects explained by region on competence $=60.626 / 76.581=79.2 \%$; SS explained within subjects by region on status $=72.446 / 82.690=87.6 \%$ ), but not on integrity (SS within subjects explained by region on integrity $=4.011 / 18.197=22.1 \%$ ).

The many interactions between the manipulated factors as well as the interactions that involved condition force us to report separate analyses of the individual speakers. In order to compare speakers across the three components, estimates were computed by averaging over the scores of the scales that received the highest loadings for a component. In Table 3, these estimates reflect the importance of the principal components for the perceptual characterization of the neutral and teacher guises of each speaker. Light gray shading is used to mark a significantly more positive evaluation of the teacher guise of a given speaker on a given component, whereas dark gray shading is used for a significantly more negative evaluation of the teacher guise of a given speaker (significance is determined here on the basis of one-way ANOVAs to compare the guises of the same speaker). 
TABLE 3. Average scores for 2 guises of 6 speakers on the 3 components emanating from the PCA

\begin{tabular}{|c|c|c|c|c|c|c|}
\hline & \multicolumn{2}{|c|}{ Status } & \multicolumn{2}{|c|}{ Competence } & \multicolumn{2}{|c|}{ Integrity } \\
\hline & Neutral & Teacher & Neutral & Teacher & Neutral & Teacher \\
\hline Rand1 & 3.11 & 2.89 & 3.99 & 3.68 & 3.29 & 3.50 \\
\hline Rand2 & 2.78 & 2.31 & 3.61 & 3.44 & 3.15 & 3.28 \\
\hline North1 & 1.94 & 1.85 & 2.85 & 2.69 & 3.31 & 3.36 \\
\hline North2 & 2.47 & 2.42 & 3.06 & 3.42 & 3.21 & 3.32 \\
\hline South1 & 1.92 & 1.96 & 2.93 & 3.02 & 3.49 & 3.61 \\
\hline South2 & 2.19 & 2.42 & 3.17 & 3.70 & 3.43 & 3.61 \\
\hline
\end{tabular}

\section{Discussion}

It should be noted, first, that the regional identification of the Rand, North, and South accents is less successful in this experiment than in the previous one (Grondelaers et al., 2010), in which the three accents concerned were correctly identified in the range between $75.8 \%$ and $90.8 \%$. Especially problematic in the present experiment is the fact that the second North speaker's accent is more frequently identified as a Randstad than as a Northern accent, with evaluations that converge more (in general) with the Randstad speakers' perceptions than with those of the other North speaker.

If the accessibility of the associated social meaning of an accent is dependent on the correctness of the identification of that accent (as argued in Grondelaers et al., 2010), then the more problematic identifiability attested in this experiment may also explain why the PCA in Table 2 does not fully replicate the PCA in the previous experiment, which returned four stable principal components: accent norm, speaker status, speaker integrity, and accent euphony. Even though the present PCA retains speaker integrity and probably (but cf. supra) also accent euphony, it conflates the individual components accent norm and speaker status we found in the previous experiment into one speaker status component. In addition, a separate speaker competence component emerges that combines scales that previously loaded on speaker status (the fact that competence should come into play in this design but not in the previous is the likely result of our manipulation of the speakers' professional profile). In spite of the similarity between the present and the previous PCA, the fact that there is little evidence in the PCA for attitude factors pertaining to the accent itself (rather than to the speaker of the accent) may raise concern in the light of what we found in Grondelaers et al. (2010). In addition to poor accent identifiability, a methodological choice that may have influenced our ratings is the decision to segment our speech stimuli in function of the implementation of the occupation variable, a choice that inevitably affects the "naturalness" of the stimuli.

In spite of these shortcomings, the experimental findings can be used to answer our research questions. Observe, first, that there is no indication that regional 
accents are sanctioned in a usage context that favors the use of the standard variety of Dutch. Only a minority of the ratings in Table 3 are significantly affected by the knowledge that the speaker is a teacher (6 of 18), and ratings appear to be affected on the speaker rather than on the accent level (although the latter observation should be handled with caution given the reservations previously fleshed out). Most importantly, there is no general downgrading of accented speech in the teacher guises, as testified by the abundance of light gray shading.

The experimental data also indicate that the question as to which is the stronger attitude trigger - regional accent or professional cues — cannot straightforwardly be answered in either/or terms. The ANOVAs clearly confirm that regional accent is the main determinant of attitude formation on the status and competence components, but not on the integrity component: Explicit information that someone is a teacher seems to render all speakers more attractive. Although the latter confirms the general positive appreciation of Belgian and Dutch teachers as reported in Verhoeven et al. (2006), as well as the high score teachers were awarded in that study on the social utility dimension, there is only one statistically significant effect on the integrity dimension. Moreover, integrity is not a very important dimension altogether (judging by the SSs provided herein). If we therefore focus our attention on status and competence, we see that the effect of occupation on these components does not appear to be random. Interestingly, the perception of speakers of the high-prestige Rand accent is negatively affected by the knowledge that a speaker is a teacher, whereas speakers of the lower-prestige accents from the North and South are positively affected when they are known to be a teacher (compare also the significant interaction region by occupation on the status and competence components).

There is, in other words, evidence for a cumulative social meaning scenario. Whereas the basic social meaning extracted from our samples is accent-based, teacher stereotypes clearly "enrich" these meanings in a nonrandom way. In the rural society indexed by the North and the South accent, any educated person enjoys some professional and social prestige; in the corporate and intellectual hub represented by the Western accent, however, teaching tends to be overshadowed by more mundane and lucrative professions. On a speculative (but entirely plausible) note, we could argue that the effect of teacher stereotypes on accent-driven social meanings is determined by the duality of the teacher image as fleshed out in the background section. Recall from our discussion of Verhoeven et al. (2006) that teachers are assessed lower than other professionals in terms of knowledge and prestige and that they suffer from "status inconsistency" because they are downgraded in terms of material status traits (especially salary) but upgraded in terms of social utility. Interestingly, all our experimental work hitherto conducted confirms that speaker status and speaker competence essentially constitute the social meaning associated with the Western Randstad accent, whereas speaker integrity-comprising social attractivity (cf. Grondelaers et al., 2010) — is a central component of the social meaning associated with the Southern accent. In this light, the downgrading of Western teachers may be caused specifically by the fact that their knowledge, 
prestige, and salary attributes fall short of the status and competence characteristics that principally define the Western image. Limburg speakers who reveal themselves to be teachers, on the other hand, profit from a status upgrade in terms of social utility (which will also affect their integrity), while their competence, which is typically assessed to be inferior as a result of the rural roots of the Limburg area, is perceived more favorably on account of the academic training any high school teacher automatically receives.

\section{GENERAL DISCUSSION}

In combination with the findings from Grondelaers et al. (2010), the data reported here indicate that regional flavoring is accepted as a socially meaningful ingredient of Standard Dutch, at least in lay conceptualizations of the standard. The fact that not even teachers of Dutch - the last gatekeepers of the standard - are downgraded for their regional accents indicates that this permissiveness applies to Standard Dutch in globo rather than to specific speakers or to a specific register. If language attitudes represent "socially derived, intellectualized or behavioral ideology" (Woolard, 1998:16), then our data confirm the anecdotal evidence for ideological change cited in the results section. Furthermore, if the Dutch language "is no longer the exclusive property of an elitist upper class of the Dutch population," because "the norm-imposing establishment is us all" (Bennis, 2003), then the question in the title that sparked off this paper has to be answered in the affirmative: In the minds of the lay speaker, Standard Dutch with a regional accent has become standard.

Although it is unclear whether SLI changed prior to language use, or whether ideological change emanated from changing language use (as Kristiansen, 2009, also notes), the present data may help to explain why standardization is a cyclical phenomenon. In reaction to Haugen's teleological model of language standardization, which is unidirectionally geared toward uniformity, Deumert and Vandenbussche (2003:10) insisted on a more circular account of standardization to the extent that a standard that has emerged out of a cluster of dialects "will again split into regional and social varieties" in the course of time so that "the cycle will start again." Interestingly, no explanation is offered for the "why" of the regionalization phase in the cycle.

As a tentative explanation, we propose that standardization-induced uniformity runs counter to one of the primary functions of human language, namely, communicating social meaning. Human speech is a vehicle for social meaning because it contains an abundance of cues for stereotyping: namely, for characterizing a person in terms of the stereotypes associated with the category/ categories he or she allegedly belongs to (Brewer, 1996:269). When an unknown British male speaks with a Received Pronunciation accent, listeners will be intuitively inclined to categorize that individual as a member of a higher social class, and they will project onto that individual the stereotypes associated with that category (viz. good breeding, private education, high income, probably 
also right-wing sympathies, etc.) in advance of any real knowledge about that person. Stereotypes, in other words, store generalized and shared knowledge about social groups that helps people interpret, explain, and predict the social world (Stangor \& Schaller, 1996), providing "patterns of expectations that help individuals function in complex social situations" (Doeleman, 1998:20). The fact that language users will naturally be inclined - in view of this function - to extract as much social meaning as possible from linguistic variation may account for the fact that no standardization attempt will ever fully succeed in eradicating variation from the linguistic signal — or, as Milroy and Milroy (1985:22) put it, "absolute standardisation of a spoken language is never achieved (the only fully standardised language is a dead language)." Even though linguistic standardization is incited and imposed from above for political, ideological, or commercial purposes, it is threatened from within by spontaneous sociopsychological motives of the language users themselves. In any society in which people have identities and allegiances that can be maintained and decoded on the basis of systematic linguistic cues, variation is bound to persist. ${ }^{3}$ It is revealing that the only medium in which Dutch is comparatively variation-freealbeit more so in Belgium than in The Netherlands (cf. Grondelaers \& Van Hout, forthcoming) - is televised news shows in which the anchor is a transmitter of facts who should not have any obvious allegiances (for neutrality's and objectivity's sake).

In this tension between uniformity and variability, regional accent variation represents the "best of both worlds." The regional accents included in this study are tiny, unobtrusive, and difficult to get rid of (even for language professionals such as teachers of Dutch whose speech is standard in every other respect). At the same time, regional accents are immensely meaningful in two ways.

First, they index stable socioregional groups that are associated with a number of (very) persistent stereotypes (Grondelaers et al., 2010). These stereotypes, moreover, are national constructs. So, even though uniformity on the level of production may be utopian in times of destandardization, perceptual uniformity clearly is attainable.

Second, accent variation is not only highly meaningful in an absolute sense. Our data suggest that regional accents represent independent social meanings that "frame" and activate (some components of) lower-level dependent social meanings. Teacher stereotypes were shown in Table 3 to be "grounded" on the accent-driven meanings, modifying them in a nonrandom way without overruling the basic accent-driven distinctions. In this capacity, they do not seem to have absolute, decontextualized social meaning themselves. The data suggest, rather, that teacher stereotypes need more basic accent-driven meanings to become activated, and that the nature and direction of this activation depends on the "sustaining" accent meaning. The fact that status and competence perceptions for teachers strongly depend on their regional background (as indexed by accent) suggests that teaching does not have independent sociosemantic meaning. It is interesting, in addition, that teachers are not downgraded in any general sense for being, for instance, "pedantic." It therefore 
seems to be the competence and status information available in the accent stereotypes that activates the counterparts of these meaning components in the teacher profile.

It will be noticed that the analysis proposed-pertaining to the robustness and independence of accent meaning - converges well with Campbell-Kibler's analysis of the sociosemantic correlations between regional and social accents and the variable (ING) that was cited in the background section. In line with Campbell-Kibler's (2009:148) assertion that the social meaning of (ING) is contextually dependent, because "[d]ifferent speakers have different aspects of their identity left open to manipulation by (ING), depending on the other information which is available to the listener," our analysis has shown a hierarchical relationship between regional accent and professional cues, to the extent that regional accent indexes independent social meanings that construe (but are also affected by) the dependent social meaning signaled by profession. Crucially, in both Campbell-Kibler's data and ours, the "other information which is available to the listener" is the regional provenance of the speaker.

\section{CONCLUSIONS}

In this paper, we have reported the results from a rating experiment designed to investigate the respective impact on attitude formation of the linguistic cue regional accent and the social cue professional occupation. A sample of 240 listeners rated two guises (neutral vs. teacher) of six speakers from three regions - the Randstad, the North (Groningen), the South (Limburg) — on 19 evaluative scales. Ratings across these scales were found to cluster in three stable principal components speaker status, speaker competence, and speaker integrity (a fourth component accent euphony could not be reliably validated). The fact that this component structure does not fully confirm the findings from a previous experiment was provisionally attributed to a lesser accent identifiability attested in the present experiment, in combination with the "unnaturalness" of the speech stimuli that was the result of the segmentation necessary to implement the two guises.

We found that ANOVAs on the ratings confirmed that both regional accent and professional occupation are determinants of attitude formation. Whereas, however, regional accent is a stronger variation determinant on the principal components speaker status and competence, occupation levels regional accent differences on the integrity dimension. Analysis of the individual speaker scores on the three components revealed that the perceived status and competence of speakers of the high-prestige accent is damaged by the information that they are high school teachers. Conversely, the perceived status and competence of speakers of low (er)-prestige accents is enhanced by self-references to their occupation in their speech.

The data collected here seem to converge on the conclusion that regional accent is the major attitude determinant available in the linguistic input, not only in 
competition with other linguistic cues (Grondelaers et al., 2010), but also in competition with explicit social cues. The experimental evidence further suggests that regional accent indexes independent social meanings that ground and frame teacher stereotypes. We have argued that it is this sociosemantic robustness and independence that renders regional accent variation meaningful and (therefore) acceptable in lay conceptualizations of Standard Dutch.

Inevitably, our findings are subject to a number of limitations. A pivotal variable that needs to be addressed in follow-up research is accent strength. Until now, we have based stimulus selection in our experiments on Adank et al.'s (2007) conclusion that the absolute majority of speakers in the Teacher Corpus have a regional accent that can be automatically identified on the basis of (no more than) vowel formants. In view of this empirical confirmation of the ubiquity of regional flavoring in the language of the best speakers of Netherlandic Dutch, we have never selected stimulus speakers in function of accent strength up to now (if only because it is so difficult to delineate and quantify regional accent). An unwanted side effect of this practice is that some speakers' accents are so tiny that their regional provenance is difficult to determine (recall that the second North speaker was erroneously classified as a Randstad speaker). It would therefore be prudent to control accent strength more rigidly in subsequent implementations, also because contrasting strong(er) and weak(er) varieties of the same accent give us the possibility to investigate whether and to what extent accent strength variation, however limited in the speech of our teachers, has consequences for their perception and evaluation.

\section{NOTES}

1. The urban concatenation of cities such as Rotterdam, Den Haag, Amsterdam, and Utrecht in the west of The Netherlands.

2. There are, of course, obvious differences: whereas (ING) is a single linguistic variable that is sociosemantically polysemous, the teacher image is a composite perceptual profile with different ingredients eliciting contrary perceptions.

3. The distinction introduced here is reminiscent of Milroy and Milroy's (1985:108ff.) opposition between social norms, which refers to the "wider social acceptability of linguistic variants" (idem), and community norms that justify the use of linguistic markers that index the speaker's allegiance to a specific regional or social group. In the same light, Crystal (1994) distinguished between "internationalism" and "identity" as opposing forces in the future of Standard English.

\section{REFERENCES}

Abrams, Dominic, \& Hogg, Michael A. (1987). Language attitudes, frames of reference, and social identity: A Scottish dimension. Journal of Language and Social Psychology 6:201-213.

Adank, Patti, Van Hout, Roeland, \& Van de Velde, Hans. (2007). An acoustic description of the vowels of Northern and Southern Standard Dutch II: Regional varieties. Journal of the Acoustical Society of America 121:1130-41.

Bennis, Hans. (2003). Hoeveel talen telt het Nederlands? Over taalvariatie en taalbeleid. In J. Stroop (ed.), Waar gaat het Nederlands naartoe? Panorama van een taal. Amsterdam: Bert Bakker. 25-34.

Brewer, Marilynn B. (1996). When stereotypes lead to stereotyping: The use of stereotypes in person perception. In C. N. Macrae, C. Stangor, \& M. Hewstone (eds.), Stereotypes and stereotyping. New York: Guilford Press. 254-275.

Campbell-Kibler, Kathryn. (2007). Accent, (ing), and the social logic of listener perceptions. American Speech 82:32-64. (2009). The nature of sociolinguistic perception. Language Variation and Change 21:135-156. 
Cargile, Aaron C. (2002). Speaker evaluation measures of language attitudes: Evidence of information processing effects. Language Awareness 11:178-191.

Cunningham-Andersson, Una, \& Engstrand, Olle. (1989). Perceived strength and identity of foreign accent in Swedish. Phonetica 46:138-154.

Crystal, David. (1994). Which English—or English which? In M. Hayhoe \& S. Parker (eds.), Who owns English?. Berkshire, UK: Open University Press. 108-114.

De Schutter, Georges. (1980). Norm en normgevoelens bij Nederlandstaligen in België. De Nieuwe Taalgids 73:93-109.

Deumert, Ana, \& Vandenbussche, Wim. (2003). Standard languages. Taxonomies and histories. In A. Deumert \& W. Vandenbussche (eds.), Germanic standardization: past to present. Impact: Studies in Language and Society 18. Amsterdam: Benjamins. 1-14.

De Vries, Jan W. (1987). De standaardtaal in Nederland. In J. de Rooij (ed.), Variatie en norm in de Standaardtaal. Amsterdam: Meertensinstituut. 143-164.

Doeleman, Rianne. (1998). Native reactions to nonnative Speech. Tilburg: Tilburg University Press.

Eckert, Penelope. (2008). Variation and the indexical field. Journal of Sociolinguistics 12(4):453-476.

Garrett, Peter. (2005). Attitude measurements. In U. Ammon, N. Dittmar, K. J. Mattheier, \& P. Trudgill (eds.), Sociolinguistics. An international handbook of the science of language and society. Vol. 2. Berlin: De Gruyter. 1251-1260.

Garrett, Peter, Coupland, Nikolas, \& Williams, Ann. (2003). Investigating language attitudes: Social meanings of dialect, ethnicity and performance. Cardiff: University of Wales Press.

Geerts, Guido, Haeseryn, Walter, De Rooij, Jaap, \& Maarten C. van den Toorn. (1984). Algemene Nederlandse Spraakkunst. Groningen/Leuven: Wolters-Noordhoff.

Geeraerts, Dirk, Grondelaers, Stefan, \& Speelman, Dirk. (1999). Convergentie en divergentie in de Nederlandse woordenschat. Een onderzoek naar kleding- en voetbaltermen. Amsterdam: Meertensinstituut.

Grondelaers, Stefan, \& Van Hout, Roeland. (forthcoming). The standard language situation in the Low Countries: Top-down and bottom-up variations on a diaglossic theme. Journal of Germanic Linguistics.

Grondelaers, Stefan, Van Hout, Roeland, \& Steegs, Mieke. (2010). Evaluating regional accent variation in Standard Dutch. Journal of Language and Social Psychology 29:101-116.

Haeseryn, Walter, Romijn, Kirsten, Geerts, Guido, De Rooij, Jaap, \& Maarten C. van den Toorn. $\left(1997^{2}\right)$. Algemene Nederlandse Spraakkunst. Groningen and Deurne: Martinus Nijhoff - Wolters Plantyn.

Haugen, Einar. (1966). Language conflict and language planning: The case of Modern Norwegian. Cambridge: Harvard University Press.

Heijmer, Tessa, \& Vonk, Roos. (2002). Effecten van een regionaal accent op de beoordeling van de spreker. Nederlands Tijdschrift voor de Psychologie 57:108-113.

Jacobi, Irene. (2008). On variation and change in diphthongs and long vowels of spoken Dutch. Ph.D. dissertation, University of Amsterdam.

Kloeke, Gesinus G. (1951). Gezag en norm bij het gebruik van Verzorgd Nederlands. Amsterdam.

Kristiansen, Tore. (2009). The macro level social meaning of late modern Danish accents. Acta Linguistica Hafniensia 41:167-192.

Lambert, Wallace E., Hodgson, Richard C., Gardner, Robert C. \& Fillenbaum, Stanley. (1960). Evaluative reactions to spoken languages. Journal of Abnormal and Social Psychology 66:44-51.

Milroy, James, \& Milroy, Lesley. (1985). Authority in language. London: Routledge \& Kegan Paul.

Oudejans, Ans, \& Meesters, Marion J. (1998). Het imago van de leraar in het basis- en voortgezet onderwijs. De uitkomsten van een kwalitatief onderzoek, Haarlem: Meesters \& Oudejans.

Silverstein, Michael. (1979). Language structure and linguistic ideology. In P. R. Cline, W. Hanks, \& C. Hofbauer (eds.), The elements: A parasession on linguistic units and levels. Chicago: Chicago Linguistic Society. 193-247.

Smakman, Dick. (2006). Standard Dutch in The Netherlands. A sociolinguistic and phonetic description. Utrecht: LOT Publishers.

Smakman, Dick, \& van Bezooijen, Renée. (1997). Een verkenning van populaire ideeën over de standaardtaal van Nederland. Taal en Tongval. Themanummer 10: Standaardisering in Noord en Zuid. 126-139.

Stangor, Charles, \& Schaller, Mark. (1996). Stereotypes as individual and collective representations. In C. Neil Macrae, C. Stangor, \& M. Hewstone (eds.), Stereotypes and stereotyping. New York: Guilford Press.

Stroop, Jan. (1998). Poldernederlands; waardoor het ABN verdwijnt. Amsterdam: Bert Bakker. 
(2000a). Naar een rehabilitatie van het ABN. Nederlandse Taalkunde 5:272-279.

(2000b). Moet het ABN zomaar naar zijn ouwemoer? Moer, Tijdschrift voor het onderwijs in het Nederlands 30:23-27

Van Bezooijen, Renée. (2001). Poldnederlands. Hoe kijken vrouwen ertegen? Nederlandse Taalkunde 6:257-271

Van de Velde, Hans, \& Houtermans, Muriel. (1999). Vlamingen en Nederlanders over de uitspraak van nieuwslezers. In E. Huls \& B. Weltens (eds.), Artikelen van de derde sociolinguïstische conferentie. Delft: Eburon. 451-462.

Van de Velde, Hans, Van Hout, Roeland, \& Gerritsen, Marinel. (1997). Watching Dutch change: A real time study of variation and change in Standard Dutch pronunciation. Journal of Sociolinguistics $1: 361-391$.

Van Haeringen, Coenraad B. (1924). Eenheid en nuance in beschaafdnederlandse uitspraak. De Nieuwe Taalgids 18:65-86.

Van Hout, Roeland. (2003). Hun zijn jongens. Ontstaan en verspreiding van het onderwerp 'hun.' In J. Stroop (ed.), Waar gaat het Nederlands naartoe? Panorama van een taal. Amsterdam: Bert Bakker. 277-286.

(2006). Onstuitbaar en onuitstaanbaar: De toekomst van een omstreden taalverandering. In N. van der Sijs, J. Stroop, \& F. Weerman (eds.), Wat iedereen van het Nederlands moet weten en waarom. Amsterdam: Bert Bakker. 42-54.

(2007). Het Europees Handvest en het Limburgs: Het politieke en het taalkundige discours. In H. Bloemhoff \& P. Hemminga (eds.), Streektaal en duurzaamheid. Berkoop-Olderberkoop: Stichting Stellingwarver Schrieversronte. 33-47.

Van Hout, Roeland, De Schutter, Georges, De Crom, Erica, Huinck, Wendy, Kloots, Hanne, \& Van de Velde, Hans. (1999). De uitspraak van het Standaard-Nederlands. Variatie en varianten in Vlaanderen en Nederland. In E. Huls \& B. Weltens (eds.), Artikelen van de derde sociolinguïstische conferentie. Delft: Eburon. 183-196.

Van Istendael, Geert. (2008). Plezier en pijn van het Nederlands. In Samen beleid maken in het GO! Onderwijs van de Vlaamse Gemeenschap. Beleidscahier nummer 3:29-33. Brussel: Ministerie van Onderwijs van de Vlaamse Gemeenschap.

Verhoeven, Jef C., Aelterman, Antonia, Rots, Isabel, \& Buvens, Ina. (2006). Public perceptions of teachers' status in Flanders. Teachers and Teaching: Theory and Practice 12:479-500.

Willemyns, Roland. (2003). Dutch. In A. Deumert \& W. Vandenbussche (eds.), Germanic standardization: past to present. Impact: Studies in Language and Society 18. Amsterdam: Benjamins. 93-125.

Woolard, Kathryn. (1998). Introduction: Language ideology as a field of enquiry. In B. B. Schieffelin, K. A. Woolard, \& P. V. Kroskrity (eds.), Language ideologies. Practice and theory. New York: Oxford University Press. 3-47.

Zahn, Christopher J., \& Hopper, Robert. (1985). Measuring language attitudes: The speech evaluation instrument. Journal of Language and Social Psychology 4:113-123. 